M.C.A.P.J. van Abeelen

Eigen spreekuur en chronische ziekten 
M.C.A.P.J. van Abeelen

\section{Eigen spreekuur en chronische ziekten}

Tweede druk

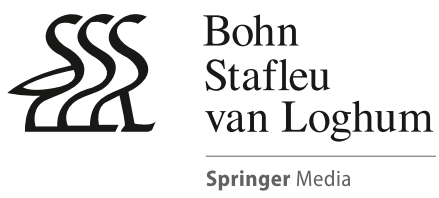




\section{ISBN 978-90-313-9974-1}

(c) Bohn Stafleu van Loghum, onderdeel van Springer Media 2013

Alle rechten voorbehouden. Niets uit deze uitgave mag worden verveelvoudigd, opgeslagen in een geautomatiseerd gegevensbestand, of openbaar gemaakt, in enige vorm of op enige wijze, hetzij elektronisch, mechanisch, door fotokopieën of opnamen, hetzij op enige andere manier, zonder voorafgaande schriftelijke toestemming van de uitgever.

Voor zover het maken van kopieën uit deze uitgave is toegestaan op grond van artikel 16b Auteurswet j het Besluit van 20 juni 1974, Stb. 351, zoals gewijzigd bij het Besluit van 23 augustus 1985, Stb. 471 en artikel 17 Auteurswet, dient men de daarvoor wettelijk verschuldigde vergoedingen te voldoen aan de Stichting Reprorecht (Postbus 3060, 2130 KB Hoofddorp). Voor het overnemen van (een) gedeelte(n) uit deze uitgave in bloemlezingen, readers en andere compilatiewerken (artikel 16 Auteurswet) dient men zich tot de uitgever te wenden.

Samensteller(s) en uitgever zijn zich volledig bewust van hun taak een betrouwbare uitgave te verzorgen. Niettemin kunnen zij geen aansprakelijkheid aanvaarden voor drukfouten en andere onjuistheden die eventueel in deze uitgave voorkomen.

NUR 891

Ontwerp omslag: Studio Bassa, Culemborg

Automatische opmaak: Crest Premedia Solutions (P) Ltd., Pune, India

Eerste druk 2006

Tweede druk 2013

Bohn Stafleu van Loghum

Het Spoor 2

Postbus 246

3990 GA Houten

www.bsl.nl 


\section{Voorwoord}

Het werk van de doktersassistent is de afgelopen jaren uitgebreid. In dit AG-katern komt een aantal chronische ziektebeelden en aandoeningen aan de orde waar de assistent nauw bij betrokken is. Ze krijgt voldoende achtergrondkennis die ze kan toepassen tijdens het houden van haar eigen spreekuur en in de contacten met chronische patiënten en hun familieleden.

Er is ook aandacht voor de specifieke problematiek van de chronische patiënt. De assistent is het eerste aanspreekpunt en door de laagdrempeligheid ook vaak iemand aan wie de patient gemakkelijk zijn of haar problemen voorlegt.

De reële casussen in dit katern zijn afkomstig uit de huisartsenpraktijk. Voor de behandeling en adviezen zijn de NHG-standaarden als uitgangspunt genomen. Ook de therapie wordt daaruit overgenomen met de generieke vermelding van de geneesmiddelen.

In deze uitgave zijn alle onderwerpen geactualiseerd en aangepast aan de laatste NHG-standaarden. De paragrafen 'Cardiovasculair risicomanagement', 'Astma en chronic obstructive pulmonary disease (COPD)' en het hoofdstuk 'Diabetes mellitus' zijn voor een groot deel herschreven. Verder hebben de onderdelen 'Het bewegingsapparaat' en 'Psychiatrie in de huisartsenpraktijk' een eigen hoofdstuk gekregen.

De ontwikkelingen gaan echter ontzettend snel, de standaarden worden regelmatig herzien en ook de farmaceutische industrie zit niet stil. Het is dus een goed advies verschillende bronnen te raadplegen, waarbij officiële sites (van het NHG en het Farmacotherapeutisch Kompas) het meest up-to-date zijn wat betreft de behandelwijze van ziekten en voor de geneesmiddelen.

Ik hoop dat dit boek een positieve bijdrage kan leveren tijdens de studie en dat het daarna als basisboek in de praktijk nog regelmatig dienst zal doen.

Marien van Abeelen, arts-docent

Oldenzaal, najaar 2012 


\section{Inhoud}

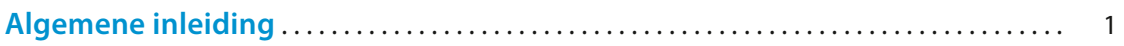

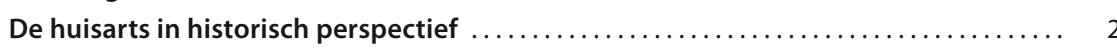

NHG-standaarden .

Een eigen spreekuur

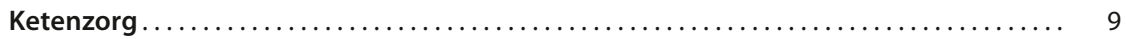

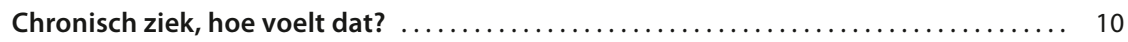

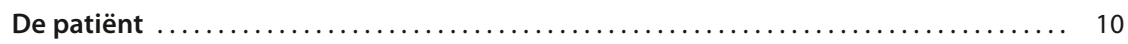

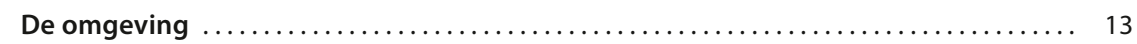

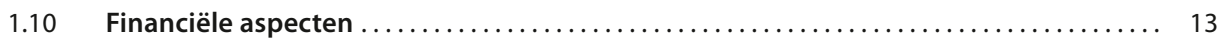

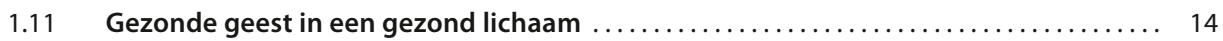

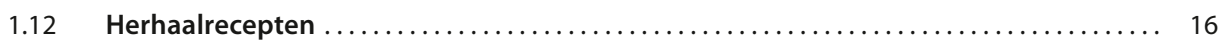

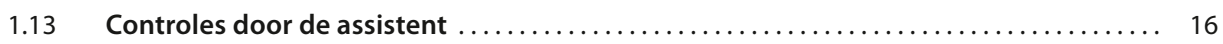

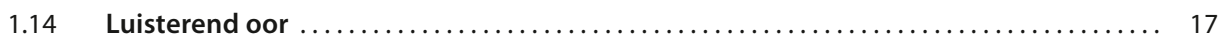

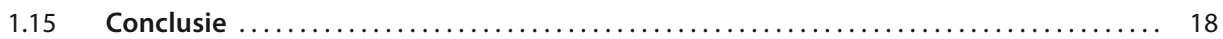

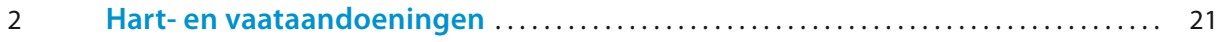

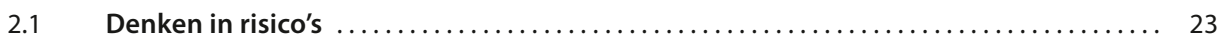

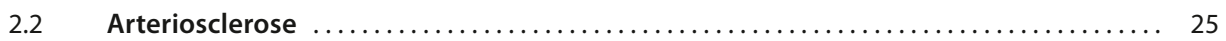

$2.3 \quad$ Risicofactoren $\ldots \ldots \ldots \ldots \ldots \ldots \ldots \ldots \ldots \ldots \ldots \ldots \ldots \ldots \ldots \ldots \ldots \ldots \ldots \ldots \ldots \ldots \ldots \ldots \ldots \ldots \ldots \ldots \ldots, 27$

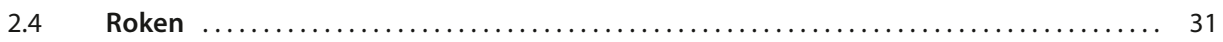

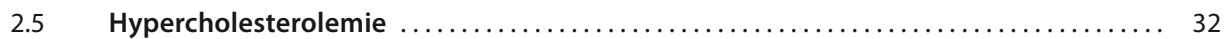

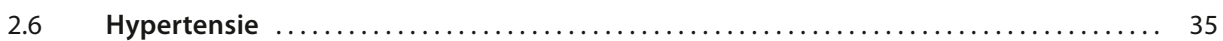

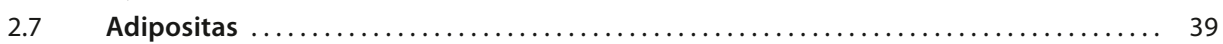

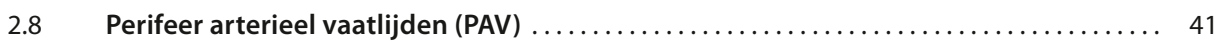

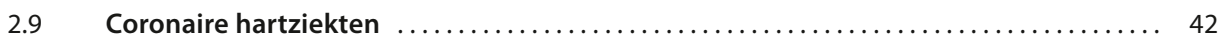

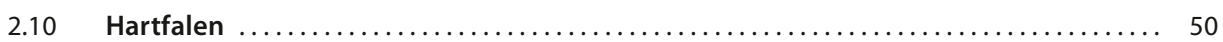

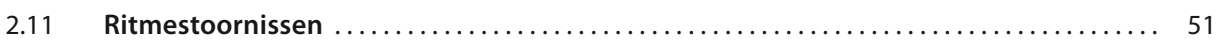

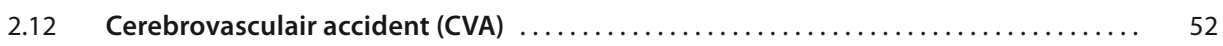

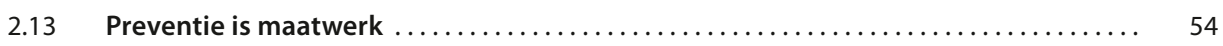

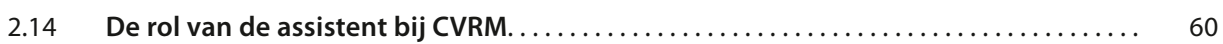

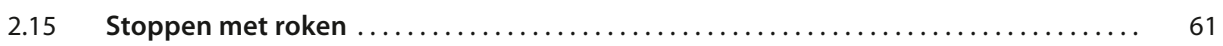

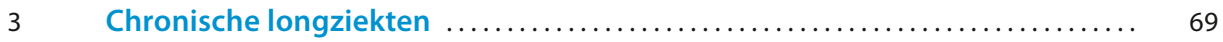

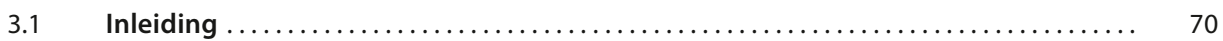

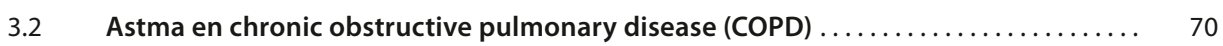

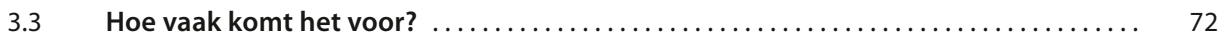

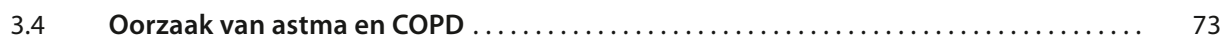

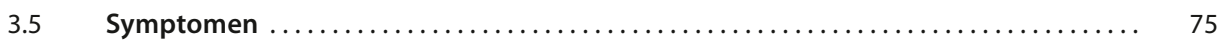

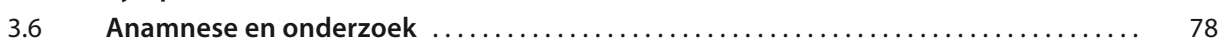

3.7 Allergieonderzoek ............................................ 78

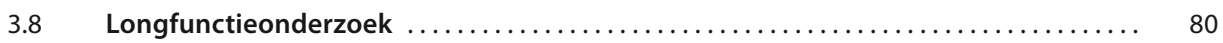

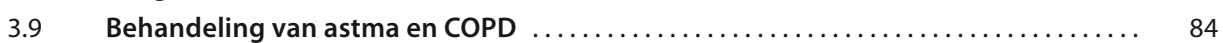

3.10 Controles van de astma- en COPD-patiënt .......................... 86 
3.11 Waar doe je het voor?

3.12 Inhalatietechnieken.

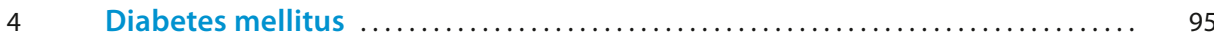

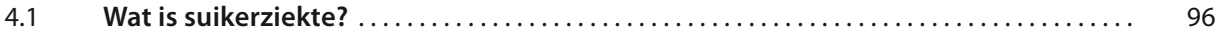

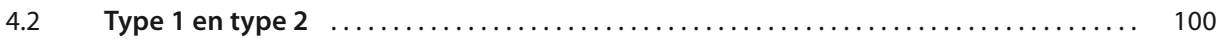

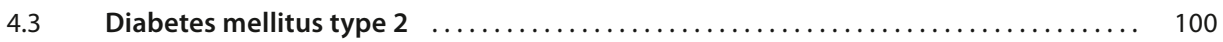

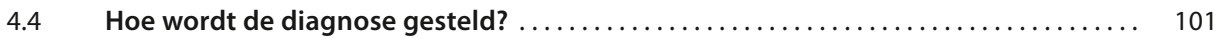

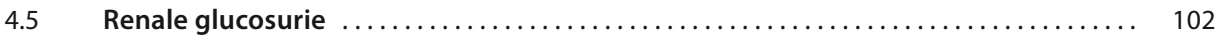

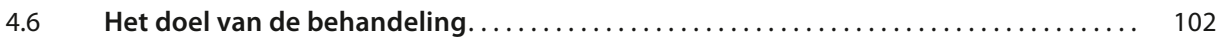

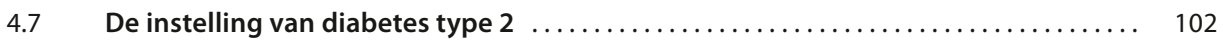

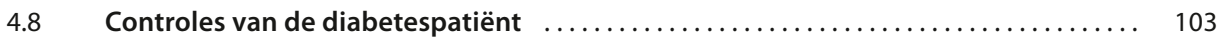

4.9 De diabetespatiënt die insuline gebruikt $\ldots \ldots \ldots \ldots \ldots \ldots \ldots \ldots \ldots \ldots \ldots \ldots \ldots . \ldots \ldots$

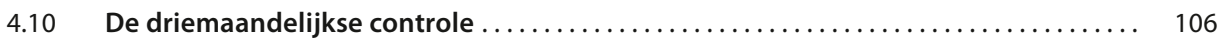

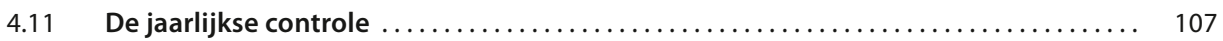

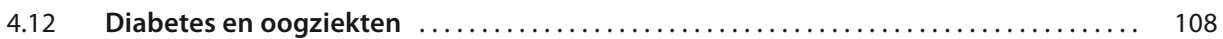

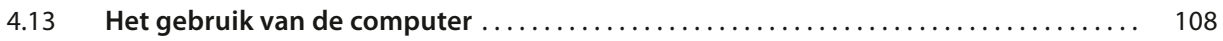

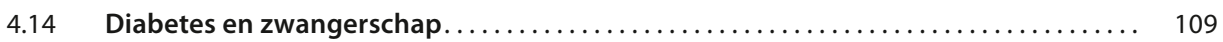

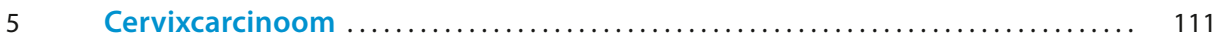

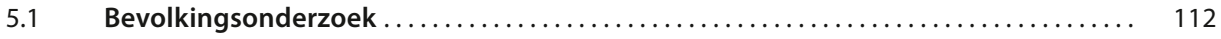

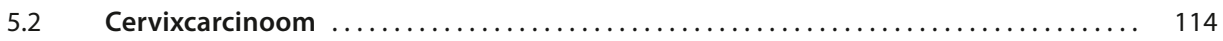

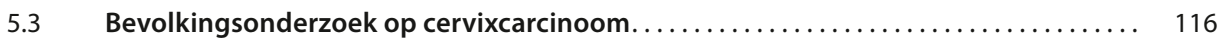

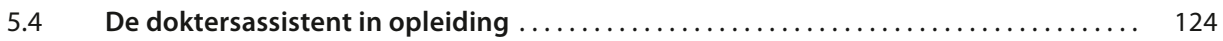

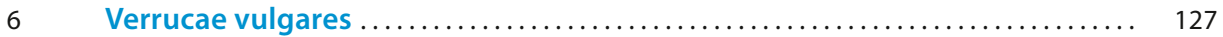

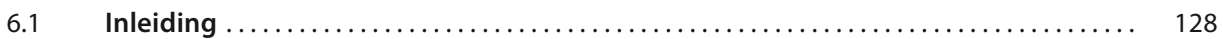

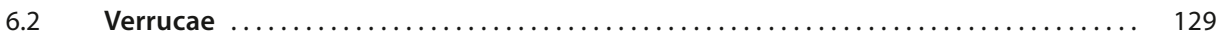

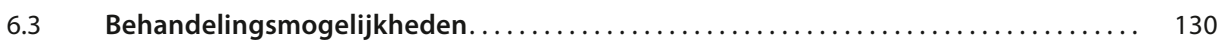

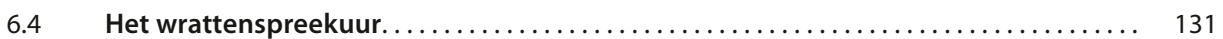

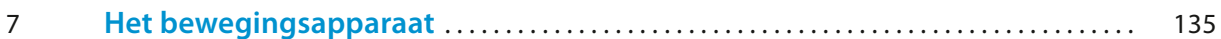

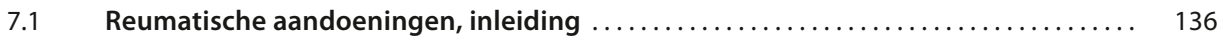

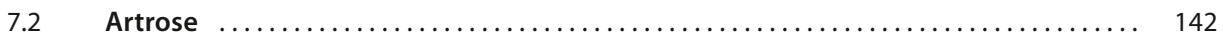

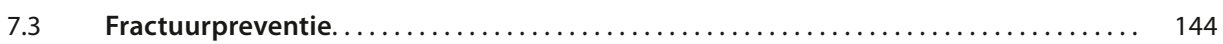

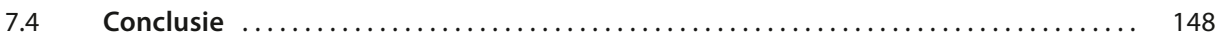

$8 \quad$ Psychiatrie in de huisartsenpraktijk........................... 151

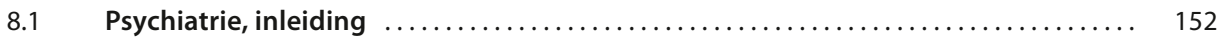

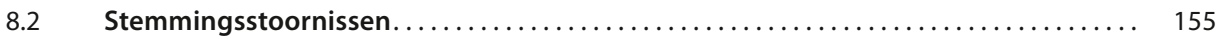

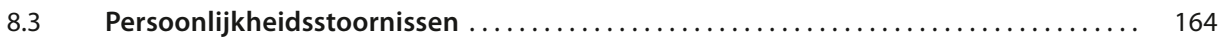

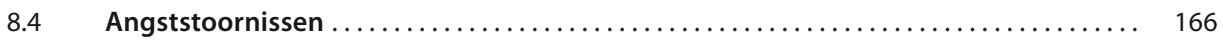

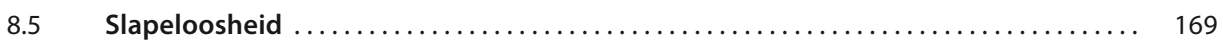

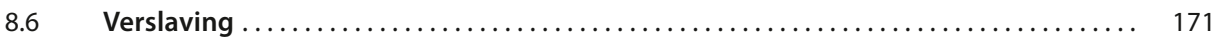

$8.7 \quad$ Cognitieve stoornissen (stoornis in kennen en weten) $\ldots \ldots \ldots \ldots \ldots \ldots \ldots \ldots \ldots \ldots$

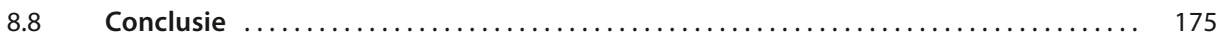


9 Veelvoorkomende chronische aandoeningen

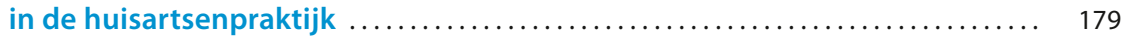

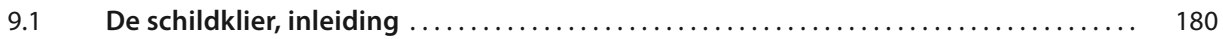

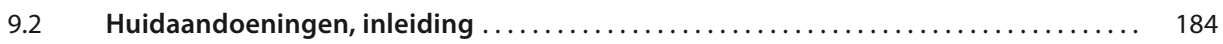

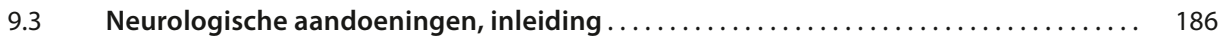

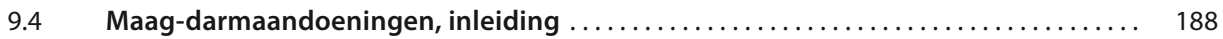

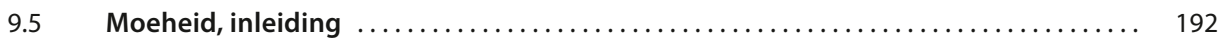

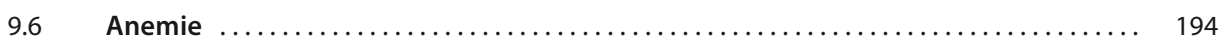

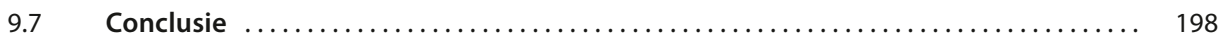

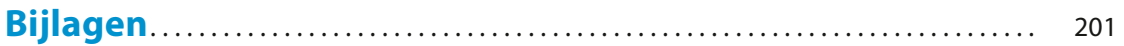

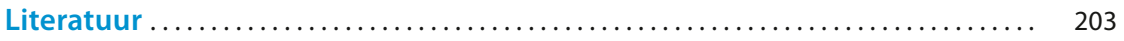

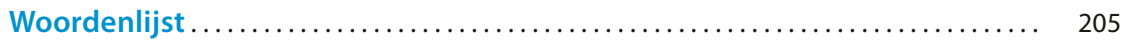

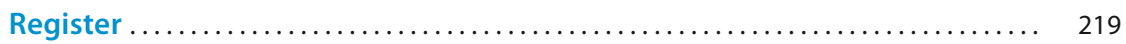

